\title{
A Theoretical Study of the Mechanism of the Desymmetrization of Cyclic meso-Anhydrides by Chiral Amino Alcohols
}

\author{
Burcu Dedeoğlu, ${ }^{[a]}$ Saron Catak, ${ }^{\perp,[b]}$ K. N. Houk, ${ }^{[b]}$ Viktorya Aviyente ${ }^{*},[a]$ \\ ${ }^{[a]}$ Department of Chemistry, Bogazici University, Bebek, Istanbul, 34342, Turkey, \\ ${ }^{[b]}$ Department of Chemistry and Biochemistry, University of California, Los Angeles, California \\ 90095-1569, USA
}

* Author to whom correspondence should be addressed: aviye@boun.edu.tr

$\perp$ Current address: Center for Molecular Modeling, Ghent University, Technologiepark 903, B9052 Zwijnaarde, Belgium

\begin{abstract}
The alcoholysis of cyclic meso-anhydrides catalyzed by $\beta$-amino alcohols has been investigated with DFT quantum mechanics to determine the mechanism of this reaction. Both nucleophilic catalysis and general base catalysis pathways are explored for methanol-induced ring opening of an anhydride catalyzed by a chiral amino alcohol. The nucleophilic pathway involves a late transition state with a high energy barrier. In this mechanism, methanolysis is expected to take place following the amine-induced ring opening of the anhydride. In the base-catalyzed mechanism, methanol attack on one carbonyl group of the meso-anhydride is assisted by the $\beta$ amino alcohol; the amine functionality abstracts the methanol proton. The chiral amino alcohol also catalyzes the reaction by stabilizing the oxyanion that forms upon ring opening of the
\end{abstract}


anhydride by hydrogen bonding with its alcoholic moiety. Both stepwise and concerted pathways have been studied for the general base catalysis route. Transition structures for both are found to be lower in energy than in the nucleophilic mechanism. Overall this study has shed light on the mechanism of the $\beta$-amino alcohol-catalyzed alcoholysis of cyclic meso-anhydrides, showing that the nucleophilic pathway is approximately $25 \mathrm{kcal} / \mathrm{mol}$ higher in energy than the general base pathway.

\section{TOC GRAPHIC}

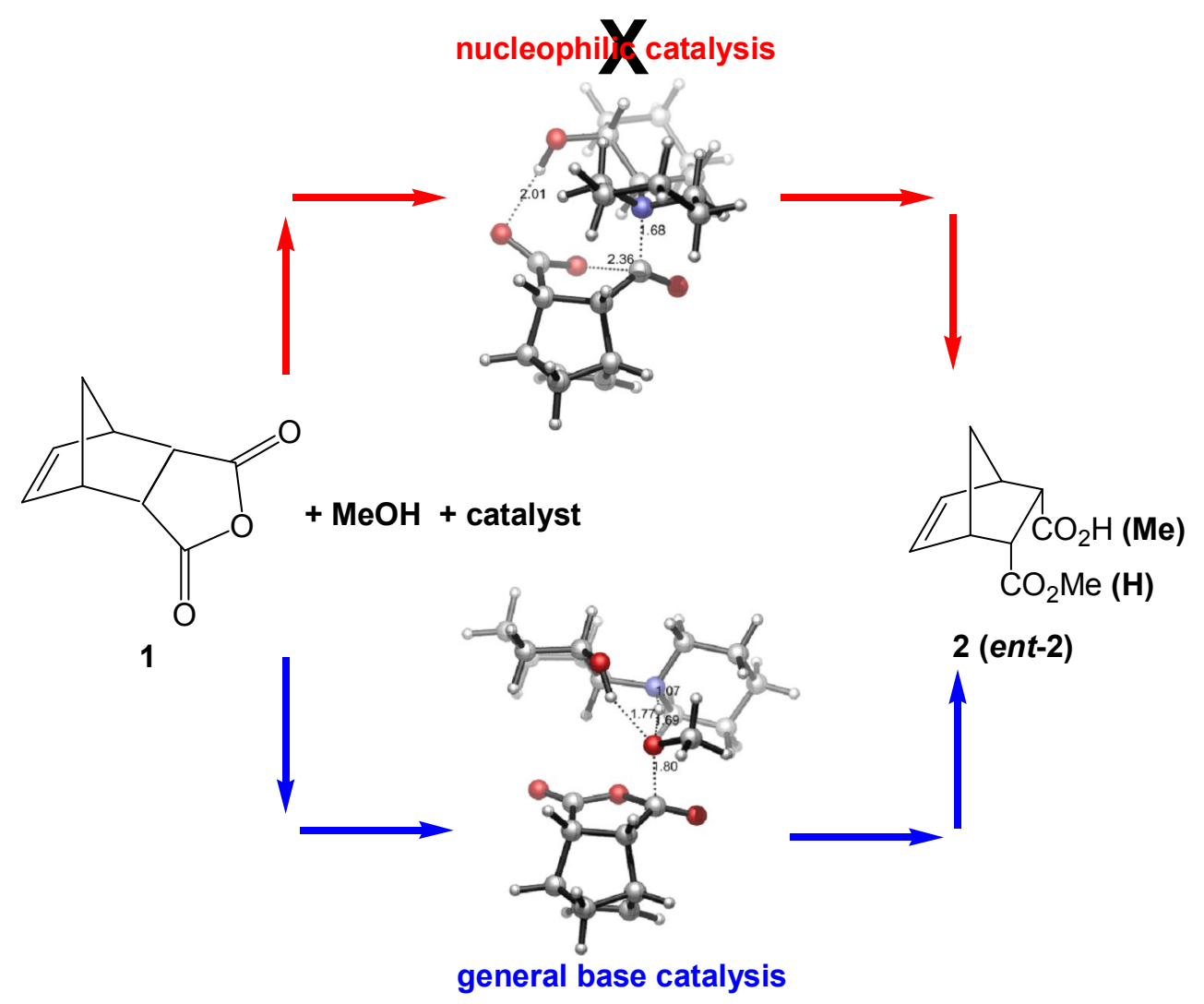

\section{INTRODUCTION}

Asymmetric desymmetrization of cyclic meso-anhydrides by selective reaction at one of the enantiotopic carbonyls has attracted considerable attention. The substrates are available through 
Diels-Alder reactions of maleic anhydride; desymmetrization to form chemically differentiated carboxy functions gives intermediates that can be easily transformed to versatile chiral building blocks for numerous synthetic applications. ${ }^{[1]}$ Very high enantioselectivities have been achieved in related enzyme-catalyzed deymmetrizations, ${ }^{[2,3]}$ but often, only one enantiomer of the product is available on this route. In contrast, anhydride openings with chiral catalysts are not limited by this restriction, because in many cases both enantiomers of the catalyst are available. Several advances in the development of non-enzymatic catalysts such as cinchona alkaloids for the asymmetric desymmetrization reactions of cyclic meso-anhydrides have been reported. ${ }^{[4]}$

Scheme 1 : Asymmetric Desymmetrization of Cyclic meso-Anhydrides.

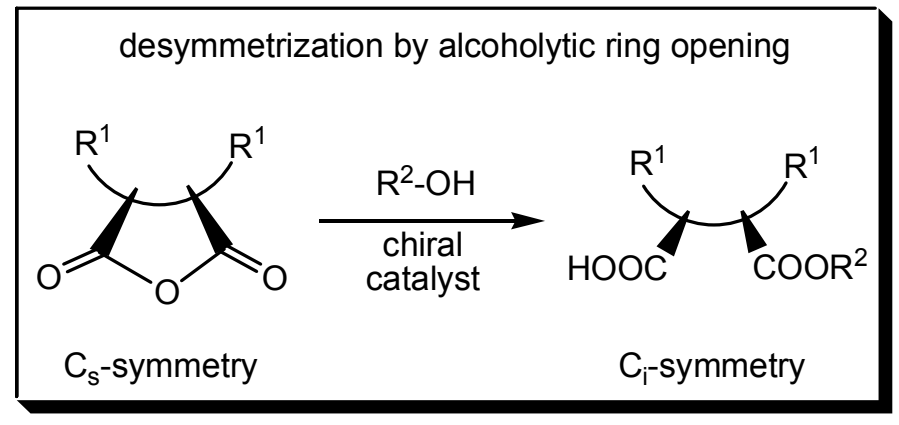

The catalytic effect of chiral amines in asymmetric desymmetrizations of cyclic anhydrides has been reviewed by Spivey, Deng and Bolm. ${ }^{[1]}$ In the case of amine-catalyzed reactions, the alcoholysis may either proceed by an initial attack of the amine on the carbonyl (nucleophilic catalysis) or a base catalyzed addition of alcohol to the anhydride (general base catalysis) (Scheme 2). In nucleophilic catalysis, the nucleophilic attack of the catalyst amine nitrogen on the anhydride is expected to form a reactive chiral acylammonium salt. Nucleophilic attack on this salt by an alcohol gives the ester product and regenerates the amine. In general base catalysis, the nucleophilic attack of the alcohol onto the anhydride is assisted by the chiral 
catalyst.

Scheme 2: Nucleophilic Catalysis and General Base Catalysis Pathways for Asymmetric Desymmetrization of Cyclic meso-Anhydrides.

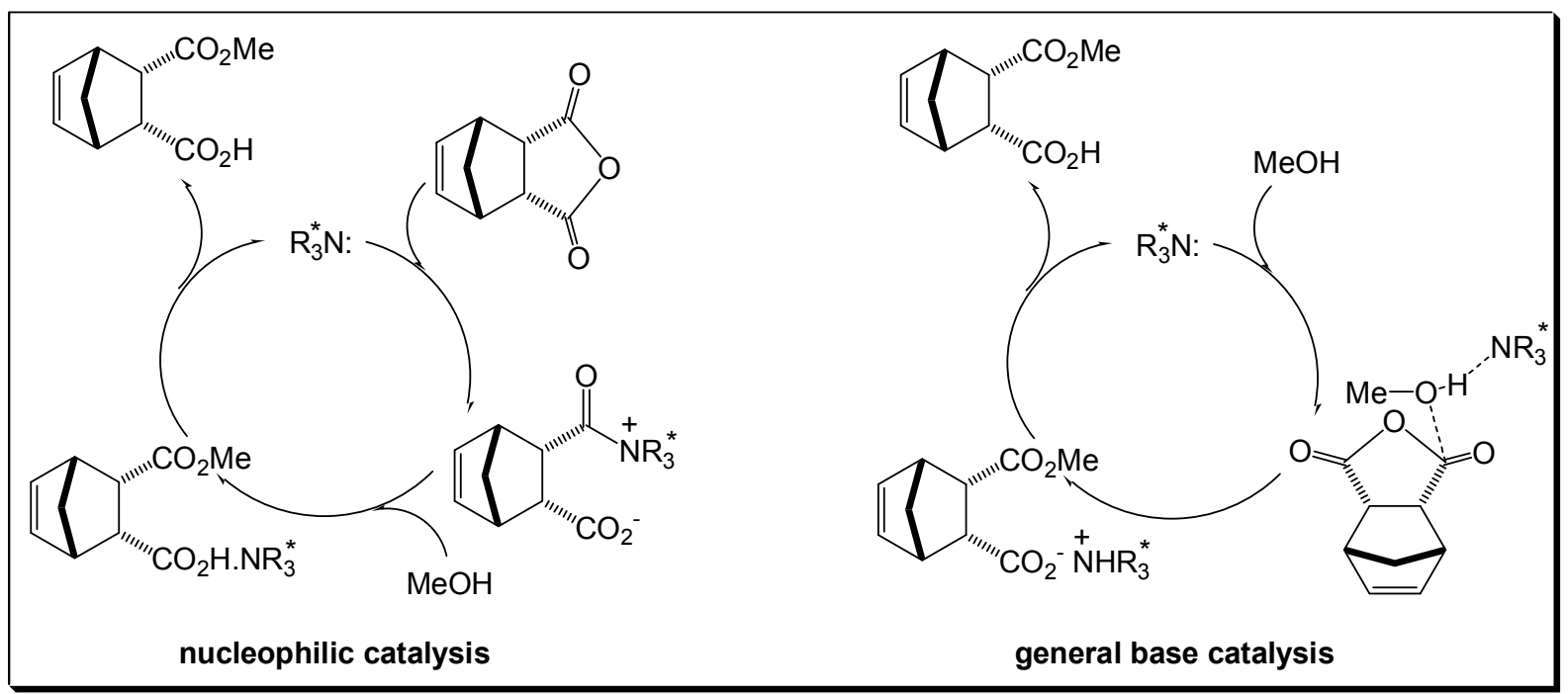

Already in his early work on alkaloid-mediated anhydride openings, Aitken suggested the formation of an acylammonium-type intermediate resulting from a nucleophilic attack of the amino group of the alkaloid onto the less-hindered face of the anhydride. ${ }^{[5]}$ This intermediate would then react with the alcohol leading to the observed monoester. Carloni's detection of an anhydride-quinine adduct by mass spectrometry supported this assumption. ${ }^{[6]}$

Oda proposed a general base catalysis, in which the quinuclidine nitrogen acted as a chiral general base rather than a nucleophile. ${ }^{[7]}$ Evidence stemmed from kinetic studies of the cinchonine-catalyzed ring opening of cis-2,4-dimethylglutaric anhydride with methanol in toluene, where a kinetic isotope effect $\left(\mathrm{k}_{\mathrm{MeOH}} / \mathrm{k}_{\mathrm{MeOD}}\right)$ of 2.3 was observed. For nucleophilic catalysis, this value was too large, favoring the suggested mechanistic alternative. 
Catalytic effects of amines in asymmetric synthesis have been subject of several theoretical investigations, and some of them include the use of alkaloid-type structures. ${ }^{[8]}$ For example, a model to explain the stereoselectivities of reductions of activated ketones on cinchona alkaloid modified platinum was developed through Vayner and Houk's computational study. ${ }^{[9]}$ In the context of the work reported here it is important to note that the mechanism of the transacylation reaction of methyl acetate with methoxide has been explored by Takano and Houk using the B3LYP/6-31+G(d) methodology, ${ }^{[10]}$ and that Zipse and co-workers have investigated the acetylation of tert-butanol with acetic anhydride catalyzed by 4-(dimethylamino)pyridine. In the latter study, both theoretical and experimental studies strongly supported a catalysis following a nucleophilic pathway. ${ }^{[11,12]}$

In order to identify the key structural components for the catalytic and enantioselective effects of the generally rather complex alkaloids, Bolm and co-workers started to evaluate the use of low molecular weight amino alcohols and investigated their efficiency as catalysts in asymmetric anhydride openings. Applying advanced variations of their early protocols, ${ }^{[13]}$ they were able to identify structurally simple $\beta$-amino alcohols such as $\mathbf{3}$, which provided products with very good enantioselectivities in excellent yields (Scheme 3). ${ }^{[1,14]}$

Scheme 3: $\beta$-Amino Alcohol-Catalyzed Enantioselective Anhydride Alcoholysis. 


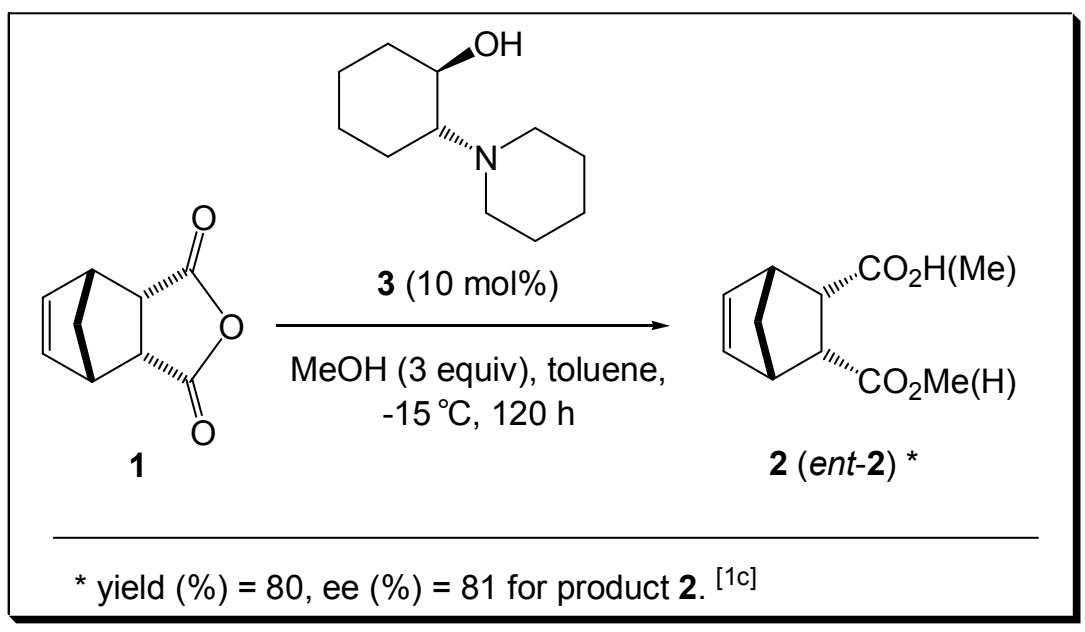

This study aims to understand the mechanistic aspects of the alcoholysis of meso-anhydrides catalyzed by chiral amines, through a computational evaluation of the probable reaction pathways mentioned earlier (Scheme 2). ${ }^{[15]}$ For this purpose, the methanolysis of anhydride 1 by $\beta$-amino alcohol catalyst $\mathbf{3}$ was investigated.

\section{COMPUTATIONAL METHODOLOGY}

Geometry optimizations were performed using denisty functional theory (DFT). [16] The B3LYP functional and $6-31+\mathrm{G}(\mathrm{d}, \mathrm{p})$ basis set were employed. ${ }^{[17]}$ Utilization of diffuse functions is especially important in the optimization of systems with charge separations. All stationary points have been characterized by a frequency analysis from which thermal corrections have also been obtained. Local minima and first order saddle points were identified by the number of imaginary vibrational frequencies. The intrinsic reaction coordinate (IRC) ${ }^{[18]}$ calculations were used to determine the species connected by each transition structure. All calculations have been carried out using the Gaussian 03 program package. ${ }^{[19]}$ The B3LYP functional is known to be adequate for geometries. However, it usually 
overestimates energy barriers; therefore, energies were further checked with the hybrid metaGGA's MPW1B95, ${ }^{[20]}$ MPWB1K ${ }^{[20]}$ and hybrid GGA M05-2X ${ }^{[21]}$ (Table 1), each known to perform well for thermochemical kinetics. The effect of a polar environment has been taken into account via the integral equation formalism-polarizable continuum (IEF-PCM) model, ${ }^{[22]}$ utilizing toluene $(\varepsilon=2.38)$ as the solvent.

\section{RESULTS and DISCUSSION}

The amine-catalyzed methanolysis of cyclic anhydride $\mathbf{1}$ has been subject to a computational investigation in order to identify the mechanism at play. For this purpose, base-catalyzed and nucleophile-catalyzed pathways (Scheme 2$)$ have been modeled, utilizing $(1 R, 2 R)$-2-(piperidin-1yl)cyclohexanol (3) as a chiral catalyst. Prior to calculations on reaction pathways, the conformational space of the catalyst has been studied.

\section{Conformational study of (1R,2R)-2-(piperidin-1-yl) cyclohexanol}

Conformers of $\mathbf{3}$ with axial or equatorial groups at the piperidine $\mathrm{N}$ are depicted in Scheme 4. Among these conformers, 3-ax and 3-eq are both capable of forming intramolecular hydrogen bonds as shown in Figure 1. Conformer 3-eq which has all substituents at the piperidinyl and the cyclohexyl ring in equatorial position, is $4 \mathrm{kcal} / \mathrm{mol}$ more stable than $\mathbf{3 - a x}$. A potential energy surface (PES) scan has been carried out for possible conformers of 3-eq, and the lowest energy conformer (shown in Figure 1) has subsequently been utilized for reaction path calculations in the methanolysis of cyclic anhydride $\mathbf{1}$.

Scheme 4. Conformers of $\mathbf{3}$ for the amine-catalyzed methanolysis of cyclic anhydride $\mathbf{1 .}$ 


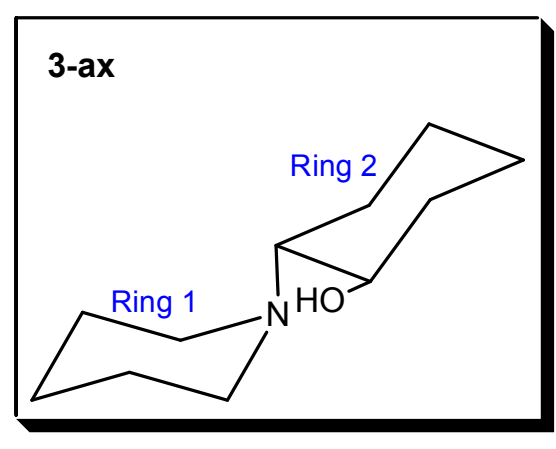

$\underset{\text { Flip }}{\text { Ring } 2}$

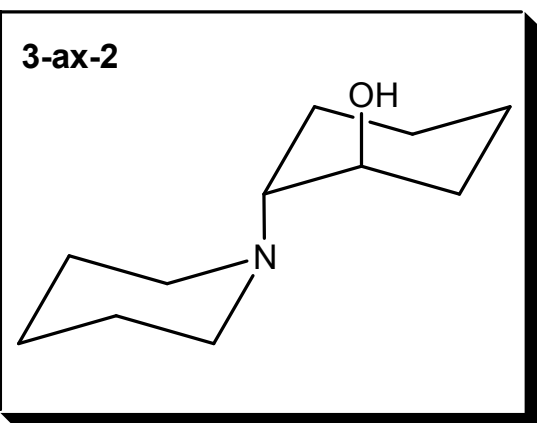

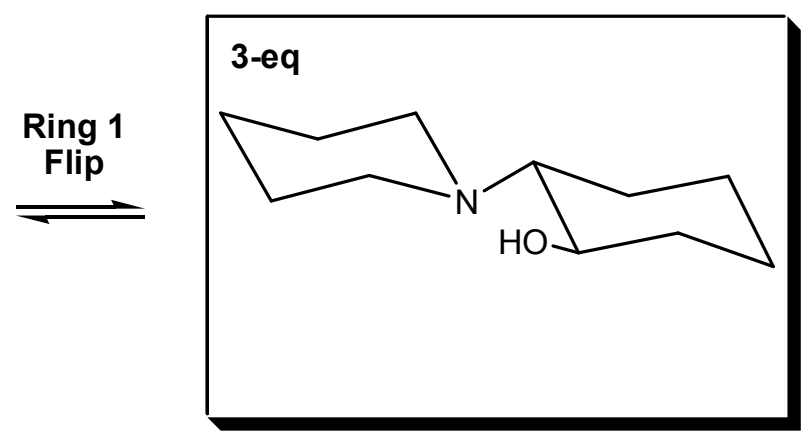

$\underset{\text { Flip }}{\text { Ring }} 2$

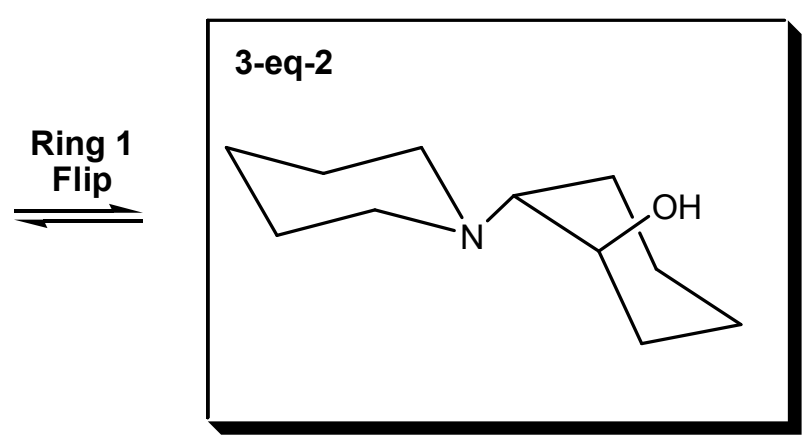




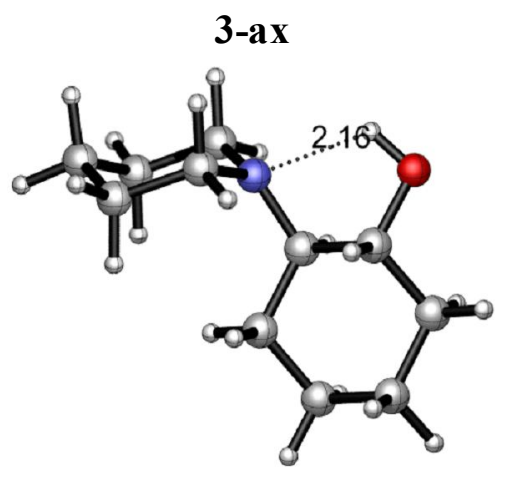

$$
\Delta G_{\mathrm{gas}}=4.1 \mathrm{kcal} / \mathrm{mol}
$$$$
\Delta G_{\text {toluene }}=4.7 \mathrm{kcal} / \mathrm{mol}
$$

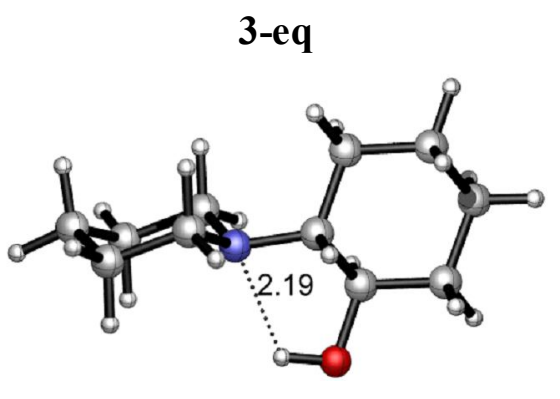

$$
\begin{gathered}
\Delta G_{\text {gas }}=0.0 \mathrm{kcal} / \mathrm{mol} \\
\Delta G_{\text {toluene }}=0.0 \mathrm{kcal} / \mathrm{mol}
\end{gathered}
$$

3-ax-2

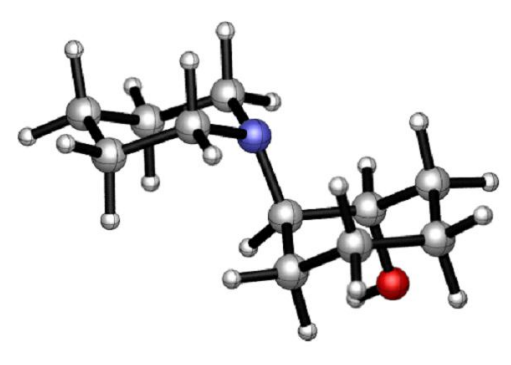

$\Delta G_{\text {gas }}=10.0 \mathrm{kcal} / \mathrm{mol}$

$\Delta G_{\text {toluene }}=10.0 \mathrm{kcal} / \mathrm{mol}$

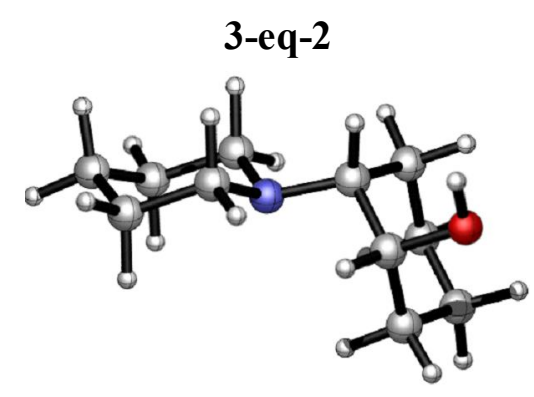

$$
\begin{gathered}
\Delta G_{\text {gas }}=6.9 \mathrm{kcal} / \mathrm{mol} \\
\Delta G_{\text {toluene }}=7.0 \mathrm{kcal} / \mathrm{mol}
\end{gathered}
$$

Figure 1. Conformers of $\mathbf{3}$ with relative free energies in gas-phase $\left(\Delta G_{\mathrm{gas}}\right)$ and toluene

$$
\left(\Delta G_{\text {toluene }}\right) .^{\mathrm{a}}
$$

${ }^{\mathrm{a}}$ Thermal free energy corrections for solvent calculations from B3LYP/6-31+G(d,p) calculations at $1 \mathrm{~atm}$ and $298 \mathrm{~K}$.

\section{Proposed Mechanisms for Asymmetric Ring Opening Reactions}

Two possible mechanisms- general base catalysis and nucleophilic catalysis -have been previously proposed for asymmetric ring opening reactions. ${ }^{[4-7]}$ Both mechanisms have been 
modeled in order to identify the most plausible pathway for the amine-catalyzed methanolysis of cyclic anhydrides $\mathbf{1}$.

\section{A. Nucleophilic Catalysis}

In the nucleophilic catalysis mechanism, the amine nitrogen of the catalyst attacks the anhydride to form a reactive chiral acylammonium salt. Next, methanol reacts with this salt leading to the product and regenerating the amine. As the catalyst nitrogen (TS-Nuc, Figure 2) approaches the carbonyl of anhydride 1, the C-O bond of the substrate elongates from $1.39 \AA$ to $2.36 \AA$ and the cyclic anhydride is cleaved. The reaction is assisted by the $-\mathrm{OH}$ group of the catalyst, which stabilizes the carboxylate moiety that forms upon ring opening.

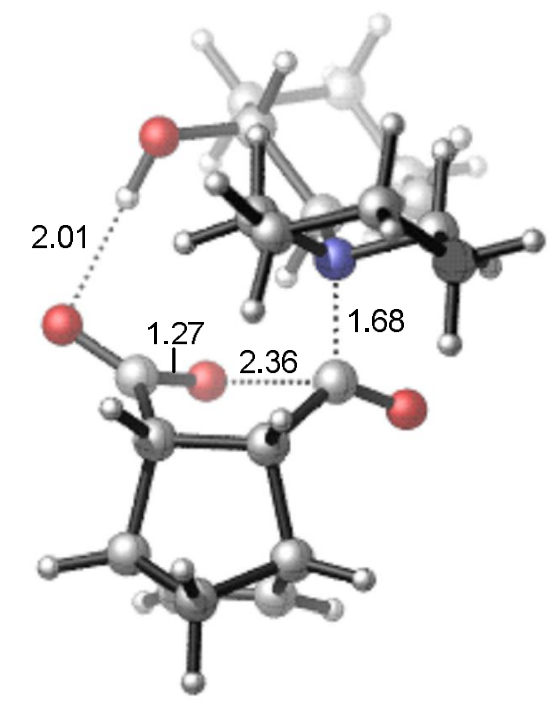

TS-Nuc

$$
\begin{gathered}
\Delta G_{\text {gas }}^{\ddagger}=62.7 \mathrm{kcal} / \mathrm{mol} \\
\Delta G_{\text {toluene }}^{\ddagger}=59.5 \mathrm{kcal} / \mathrm{mol}
\end{gathered}
$$

Figure 2. Transition structure for nucleophilic catalysis of anhydride $\mathbf{1}$ and free energy of activation in gas-phase $\left(\Delta G^{\ddagger}\right.$ gas $)$ and toluene $\left(\Delta G^{\ddagger}\right.$ toluene $)(\mathrm{B} 3 \mathrm{LYP} / 6-31+\mathrm{G}(\mathrm{d}, \mathrm{p})){ }^{\mathrm{a}}$

${ }^{a}$ Thermal free energy corrections for solvent calculations from B3LYP/6-31+G(d,p) calculations at 1atm and 298K. 
Carloni et al. proposed that the desymmetrization reaction of meso-anhydrides catalyzed by cinchona alkaloids proceeds through the formation of an adduct between quinidine and anhydride (Scheme 5). ${ }^{[6]}$ The hypothetical structure, proposed by Carloni forms through the nucleophilic attack of quinidine that leads to ring opening of anhydride. The ring opening of TSNuc and Carloni's intermediate are assisted by hydrogen bonds between the $-\mathrm{OH}$ of the catalyst and the anhydride. The structure proposed by Carloni is very similar to TS-Nuc, nevertheless different catalysts and anydrides have been used in the latter, so the stability of TSNuc cannot be argued based on this finding.

Scheme 5 . Active intermediate proposed by Carloni. ${ }^{[6]}$

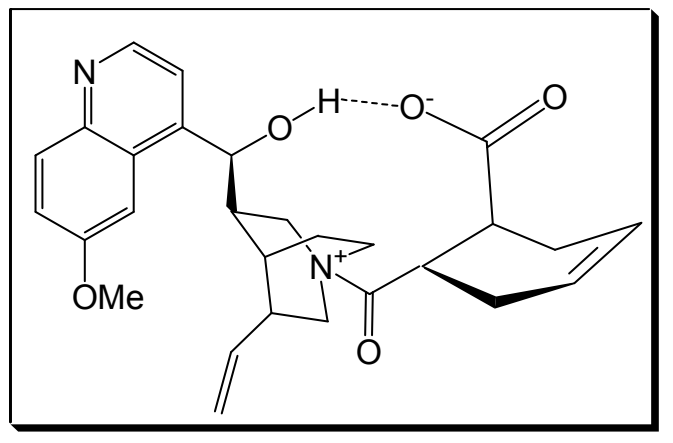

The transition state, TS-Nuc, is late with a high energy barrier $\left(\Delta G^{\ddagger}\right.$ gas $=62.7 \mathrm{kcal} / \mathrm{mole}$, Figure 2). In this mechanism, the stereochemistry of the product, $\mathbf{2}$, is established in the initial step, before methanol attacks the acylammonium salt. The reaction is likely to be stereoselective, and the transition state in Figure 2 leads to the observed major product. However, in the case of TSNuc, the activation free energies are much too high to be operative. 


\section{B. General Base Catalysis}

In the alternative mechanism, the catalyst acts as a chiral general base rather than a nucleophile. The methanol attack on the carbonyl is assisted by the catalyst nitrogen through deprotonation. Deprotonation of the methanol yields methoxide, which is far more nucleophilic than methanol, enhancing the nucleophilic attack that leads to ring opening of the anhydride. The catalyst also stabilizes- through H-bond by the alcohol moiety -the oxyanion formed as a result of ring opening. The stereochemistry of the final product is determined by which enantiotopic carbonyl is attacked by methoxide. In the base catalyzed mechanism, the ring opening reaction may proceed via a stepwise (TS-Base-Step1) or a concerted pathway (TS-Base-Conc) (Figure 3).

In the concerted pathway, attack of methanol is accompanied by a simultaneous ring opening of the anhydride in a single step. In the stepwise pathway, nucleophilic attack of methanol on the anhydride leads to the formation of a tetrahedral intermediate (INT), which then undergoes ring opening to yield the final product. The energies computed for these mechanisms are shown in Figure 3.

In the transition state of the concerted pathway, TS-Base-Conc, as methanol attacks anhydride 1, the forming CO distance is $1.80 \AA$. Methanol is deprotonated by the basic catalyst; the forming NH distance is $1.07 \AA$. Finally, product 2 forms and the catalyst is regenerated. The process is endothermic by $4.4 \mathrm{kcal} / \mathrm{mol}\left(\Delta G_{\text {toluene }}=5.0 \mathrm{kcal} / \mathrm{mol}\right)$; Figure 3$)$.

The first step in the stepwise general base catalysis mechanism is the same, but a tetrahedral intermediate is formed instead. Transition structure TS-Base-Step1 in Figure 3 illustrates the complex between anhydride 1, the catalyst and methanol. This complex is stabilized through a 
hydrogen bond network between the nitrogen atom of the catalyst and the hydrogen atom of methanol, stabilizing the oxyanion. IRC calculations have verified that TS-Base-Step1 connects the intermediate (INT) to the reactants. The intermediate, INT is $27.2 \mathrm{kcal} / \mathrm{mol}(28.5 \mathrm{kcal} / \mathrm{mol}$ in toluene) higher in energy than the reactants. The second step requires only a small energy barrier of $3.2 \mathrm{kcal} / \mathrm{mol}(1.9 \mathrm{kcal} / \mathrm{mol}$ in toluene) and through TS-Base-Step2 ring opening leads to the final product, and the catalyst is regenerated (Figure 3).

The $26.8 \mathrm{kcal} / \mathrm{mol}$ free energy difference $(23.4 \mathrm{kcal} / \mathrm{mol}$ in toluene) between the transition states of the nucleophilic catalysis (TS-Nuc) and base catalysis mechanisms (TS-Base-Conc) shows that the general base catalysis mechanism for asymmetric ring opening reactions is most likely to be the operative pathway. Nevertheless, the computed activation energy is quite high compared to the facility with which the reactions occur. 


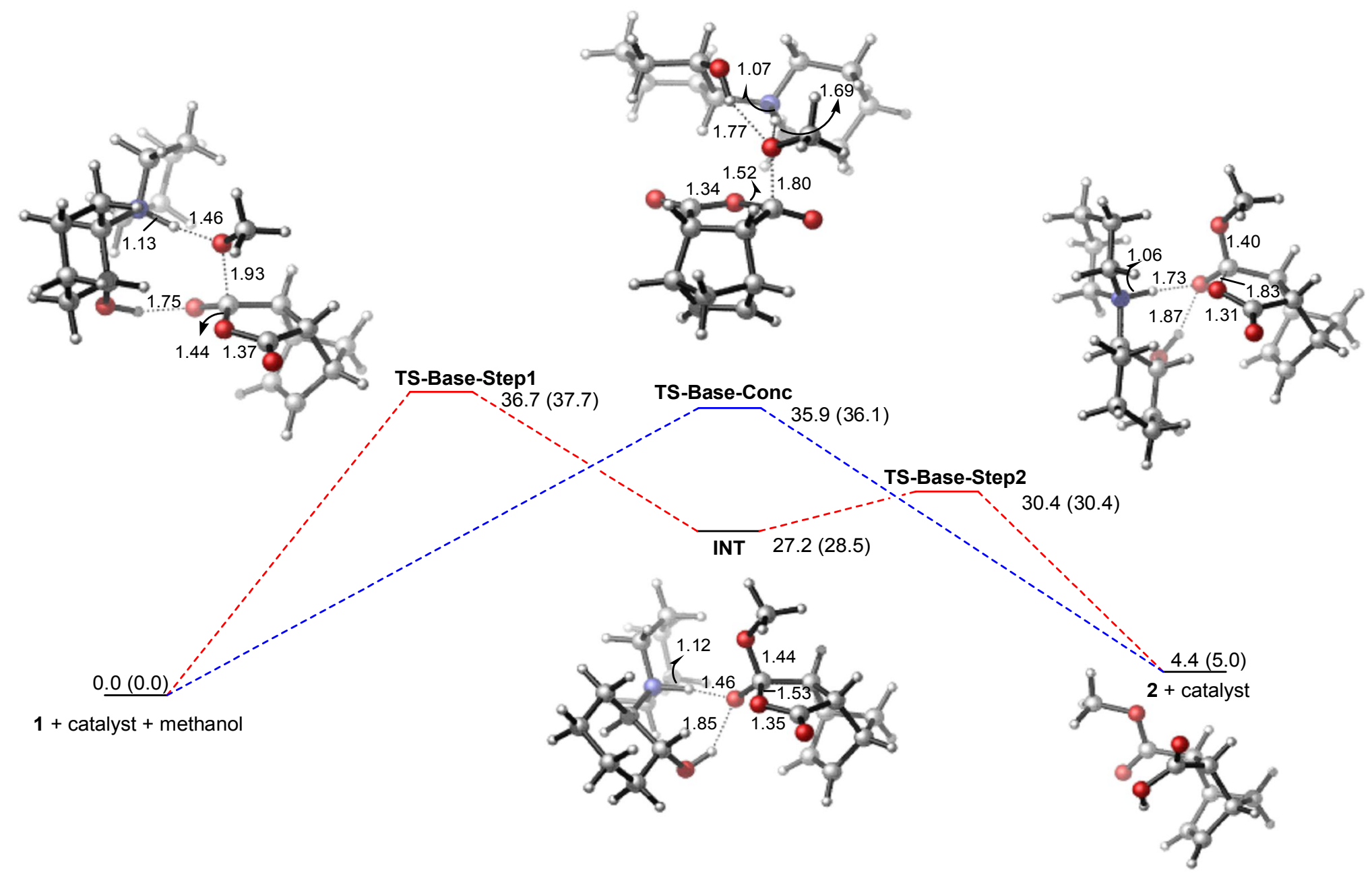

Figure 3. B3LYP/6-31+G(d,p) free energy profile, $\Delta G_{\text {gas }}\left(\Delta G_{\text {toluene }}\right)$, for concerted and stepwise base catalysis pathways. ${ }^{\text {a }}$

${ }^{a}$ Thermal free energy corrections for solvent calculations from B3LYP/6-31+G(d,p) calculations at 1 atm and $298 \mathrm{~K}$. 


\section{Effect of Excess Methanol on Reactions Energetics}

Asymmetric desymmetrization reactions with $\beta$-amino alcohol $\mathbf{3}$ were conducted using 1 equivalent of the catalyst and 3 equivalents of methanol. ${ }^{[1 \mathrm{c}, 14]}$ In order to better mimic the reaction conditions, three methanol molecules were included in the calculations to explore the concerted base-catalyzed reaction pathway. One methanol acted as the nucleophile and the other two were stabilizing carbonyl oxygens of the anhydride 1 through hydrogen bonds (Figure 4).
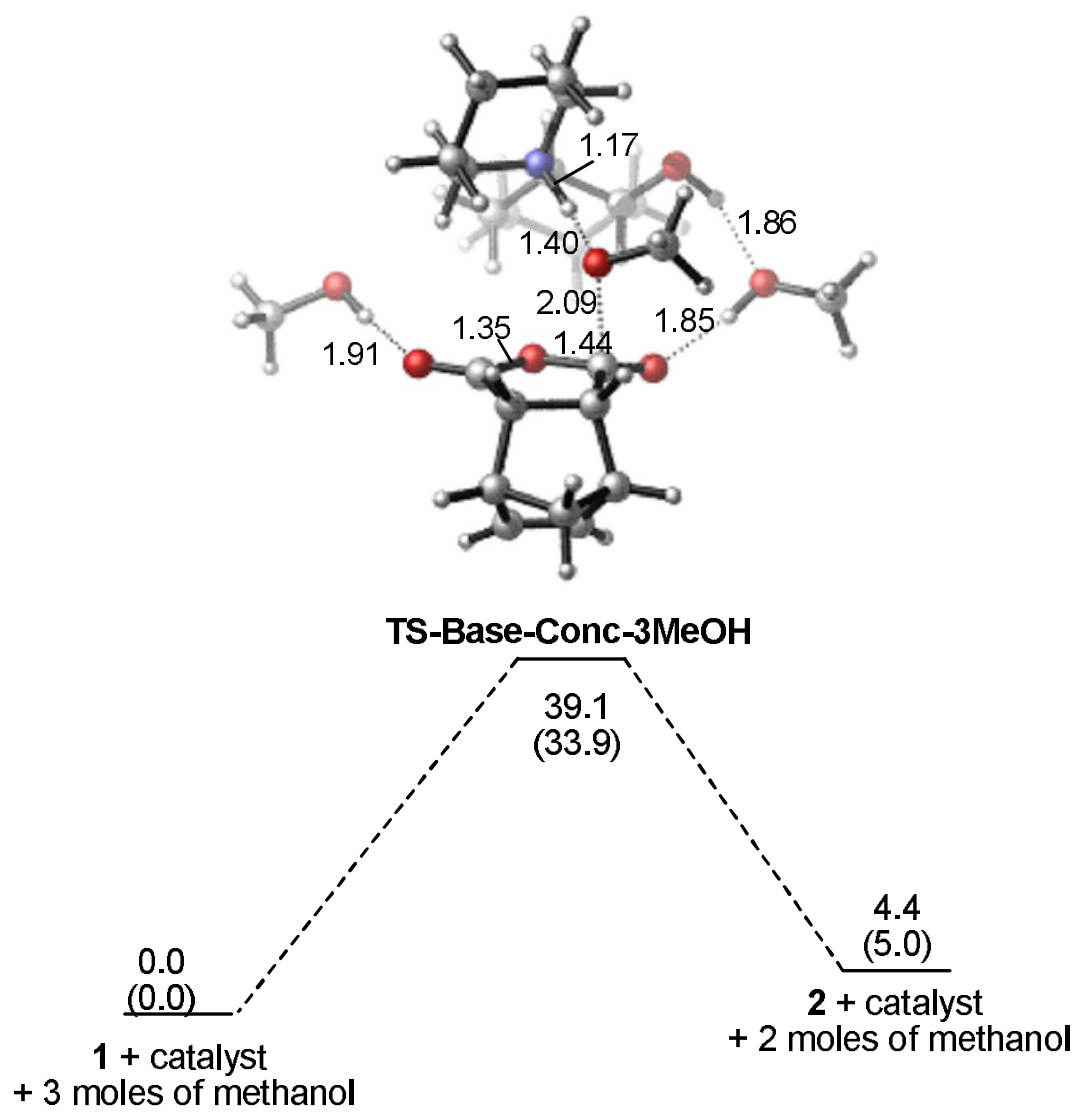

Figure 4. B3LYP/6-31+G(d,p) free energy profile, $\Delta G_{\text {gas }}\left(\Delta G_{\text {toluene }}\right)$, for the concerted base catalyzed mechanism with excess methanol (anhydride +3 methanol + catalyst). ${ }^{\mathrm{a}}$

${ }^{\mathrm{a}}$ Thermal free energy corrections for solvent calculations from B3LYP/6-31+G(d,p) calculations at $1 \mathrm{~atm}$ and $298 \mathrm{~K}$.

TS-Base-Conc-3MeOH (Figure 4) is very similar to TS-Base-Conc except for additional Hbonds between the catalyst, methanol and anhydride 1. As the nucleophilic methanol 
approaches, a bond elongation is observed in the anhydride ring, where the carbon oxygen bond lengthens from $1.39 \AA$ to $1.44 \AA$, and methanol is deprotonated by the catalyst. Peripheral methanols help stabilize the charge developing as the ring opens. TS-Base-Conc3MeOH and TS-Base-Conc are very similar in terms of free energy, but TS-Base-Conc3MeOH is better stabilized in toluene compared to the one methanol system, TS-Base-Conc $\left(\Delta \Delta G_{\text {toluene }}^{\ddagger}=2.2 \mathrm{kcal} / \mathrm{mol}\right)$.

\section{Effect of Methodology and Implicit Solvation on Reaction Energetics}

Activation free energies for the nucleophilic catalysis and concerted-general base catalysis mechanism are given in Table 1. The results show a clear preference for the concerted-general base catalysis over the nucleophilic catalysis mechanism for all functionals. For all methods, the energy difference between nucleophilic and base catalysis is approximately $25 \mathrm{kcal} / \mathrm{mol}$, both in vacuo and toluene. While the base catalysis barriers are relatively unaffected by the solvent, the nucleophilic catalysis barriers show a slight decrease in barrier, due to the stabilization of the transition state in toluene. Note that M05-2X gives activation barriers quite consistent with experimental results at room temperature.

Table 1. Free energies of activation for nucleophilic and concerted-base catalysis pathways in gas-phase $\left(\Delta G_{\text {gas }}\right)$ and toluene $\left(\Delta G_{\text {toluene }}\right)$ with MPW1B95, MPWB1K and M05-2X on B3LYP/6-31+G(d,p) geometries. ${ }^{\text {a }}$

\begin{tabular}{lcccccc} 
& \multicolumn{2}{c}{ Nucleophilic Catalysis } & & \multicolumn{2}{c}{ Concerted-Base Catalysis } \\
\cline { 2 - 3 } & $\Delta G_{\text {gas }}^{\ddagger}$ & $\Delta G_{\text {toluene }}^{\ddagger}$ & & $\Delta G_{\text {gas }}^{\ddagger}$ & $\Delta G_{\text {toluene }}^{\ddagger}$ \\
\cline { 1 - 1 } B3LYP/6-31+G(d,p) & 62.7 & $59.5(56.3)^{\mathrm{b}}$ & & 35.9 & $36.1(39.2)^{\mathrm{b}}$ \\
MPW1B95/6-31+G(d,p) & 57.3 & 53.9 & & 30.5 & 30.7 \\
MPWB1K/6-31+G(d,p) & 77.7 & 73.9 & & 49.9 & 50.0
\end{tabular}


${ }^{\mathrm{a}}$ Thermal free energy corrections for solvent calculations from B3LYP/6-31+G(d,p) calculations at 1atm and 298K. ${ }^{\text {b }}$ Acetone as solvent. ${ }^{c}$ Optimized with M05-2X/6-31+G(d,p).

The energetics of the nucleophilic catalysis and the concerted-general base catalysis mechanisms were calculated in toluene $(\varepsilon=2.38)$ and in acetone $(\varepsilon=20.56)$ (Table 1$)$. The free energy of activation for the nucleophilic catalysis decreases as the polarity of the solvent increases. In contrast, in the concerted-general base catalysis, the activation energies increase with increasing solvent polarity. Compared to toluene $(\varepsilon=2.38)$ TS-Nuc is stabilized by 3.2 $\mathrm{kcal} / \mathrm{mol}$ in acetone $(\varepsilon=20.56)$, which is possibly due to the stabilization of the acylammonium salt, a zwitterionic intermediate in a polar medium. TS-Base-Conc is slightly destabilized as the polarity of the solvent increases.

\section{Stereoselectivity}

Figure 5 depicts the reaction profile for the formation of the product ent2 (Scheme 3). The transition structure TS-ent2-Base-Step1 leading to the formation of ent2 illustrates a complex between anhydride $\mathbf{1}$, the catalyst and methanol. This complex is again stabilized through a hydrogen bond network between the nitrogen atom of the catalyst and the hydrogen atom of methanol, as in the case of TS-Base-Step1. Once the intermediate has formed, the second step through TS-ent2-Base-Step2 requires a minute energy barrier of $0.1 \mathrm{kcal} / \mathrm{mol}(0.2 \mathrm{kcal} / \mathrm{mol}$ in toluene); subsequent ring opening leads to the final product, ent2, and the catalyst is regenerated. 


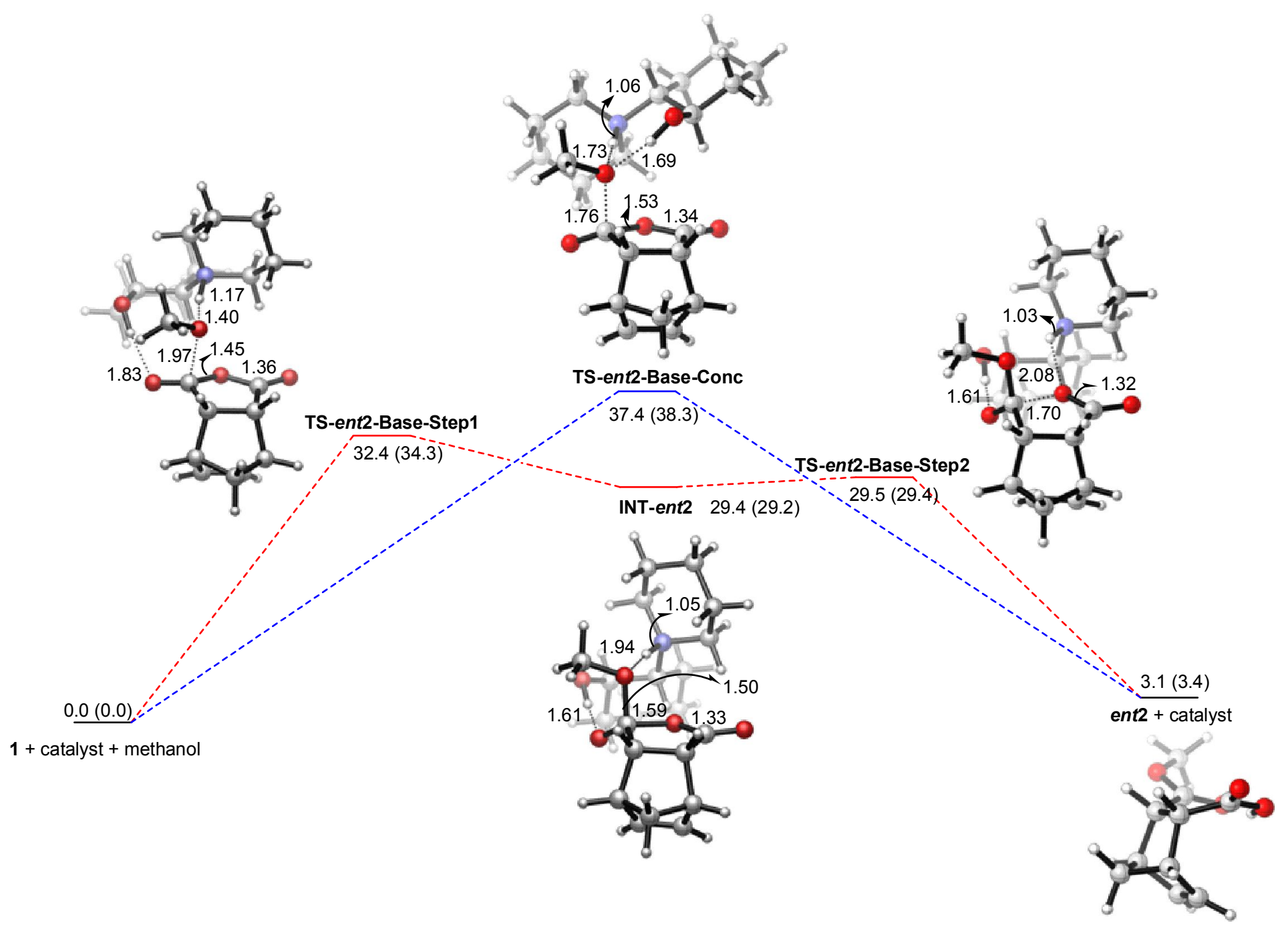

Figure 5. B3LYP/6-31+G(d,p) free energy profile, $\Delta G_{\text {gas }}\left(\Delta G_{\text {toluene }}\right)$, for concerted and stepwise base catalysis pathways. ${ }^{\text {a }}$

${ }^{a}$ Thermal free energy corrections for solvent calculations from B3LYP/6-31+G(d,p) calculations at 1atm and 298K. 
The energy difference of $4.3 \mathrm{kcal} / \mathrm{mol}(3.4 \mathrm{kcal} / \mathrm{mol}$ in toluene $)$ between the transition structures TS-Base-Step1 (Figure 3) and TS-ent2-Base-Step1 (Figure 5) leading to the formation of products, $\mathbf{2}$ and $\boldsymbol{e n t} \mathbf{2}$, respectively, mainly stems from the relative orientations of the piperidine and cyclohexanol rings of the catalyst. While in TS-ent2-Base-Step1 the catalyst looks like 3-eq (Figure 1), this is not the case for the catalyst in TS-Base-Step1, (Figure 5). In TS-Base-Conc and TS-ent2-Base-Step1 catalyst conformations are almost identical, as shown in Figure 6. However, there is still an energy difference of $3.5 \mathrm{kcal} / \mathrm{mol}$ (1.8 $\mathrm{kcal} / \mathrm{mol}$ in toluene), which can be attributed to the difference in the nature of hydrogen bonds involved; in TS-Base-Conc, the catalyst assists the reaction by hydrogen bonding to the methanol oxygen via its alcoholic entity, while in TS-ent2-Base-Step1 the catalyst-OH is hydrogen bonded to the carbonyl oxygen of the anhydride. The location and nature of the hydrogen bonds seem to play an important role, since they render the nucleophilic attack by methanol easier. Figure 6 gives a comparative picture of the dihedral angles between the piperidine and cyclohexanol rings of the catalyst for transition states TS-Base-Conc, TSent2-Base-Conc, TS-Base-Step1, TS-ent2-Base-Step1 against 3-eq. 


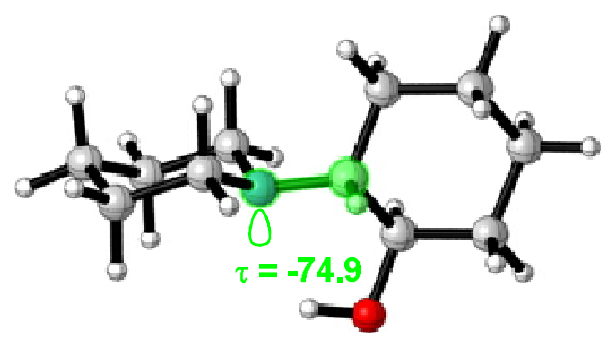

3-eq
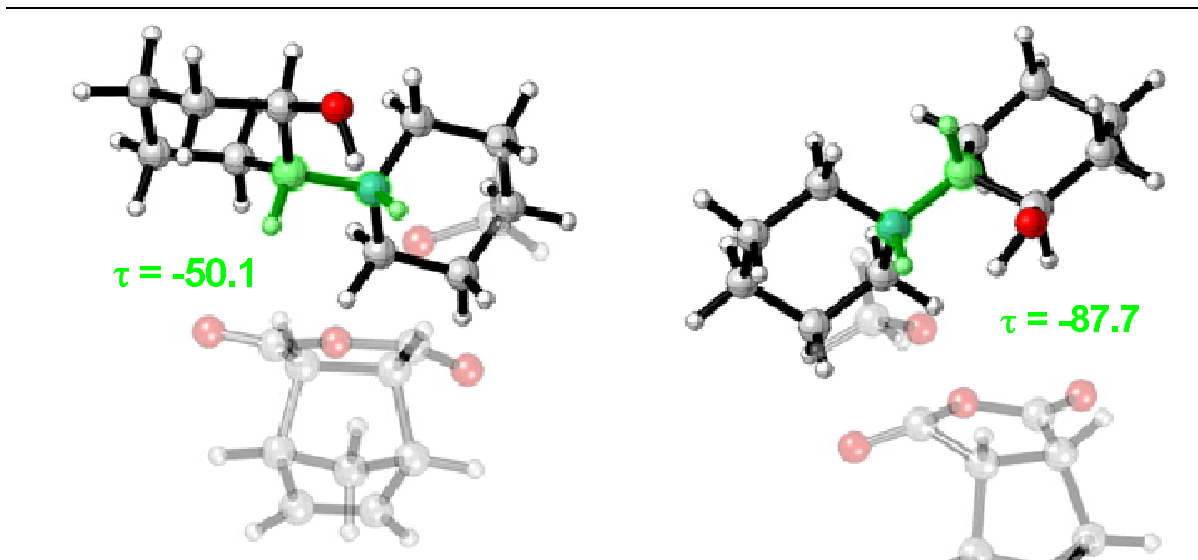

TS-Base-Conc

TS-ent2-Base-Conc

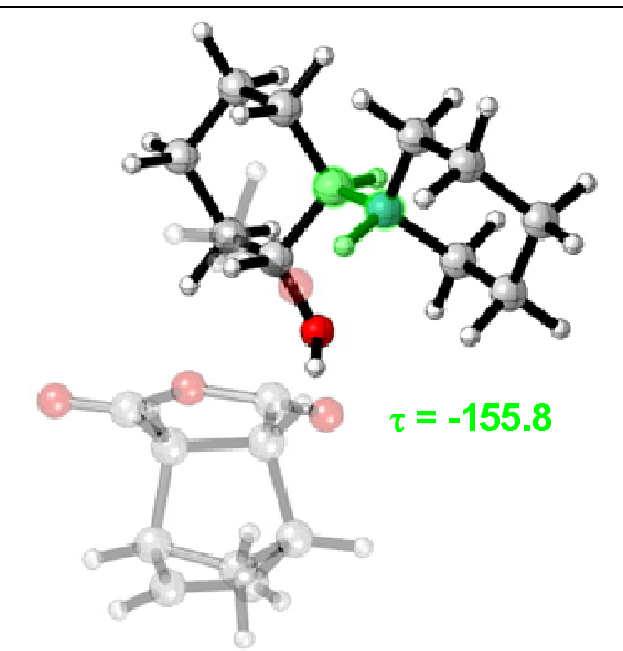

TS-Base-Step1

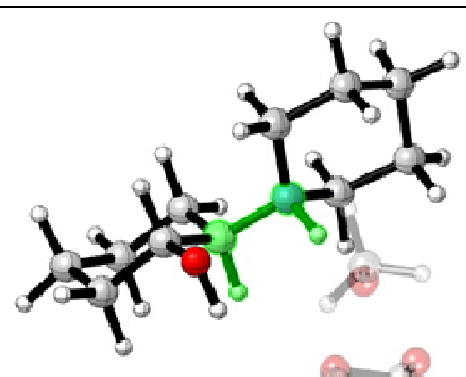

$\tau=-47.2$

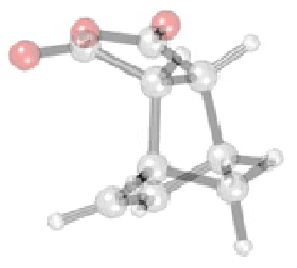

TS-ent2-Base-Step1

Figure 6. Catalyst dihedral angles for transition states TS-Base-Conc, TS-ent2-Base-Conc, TS-Base-Step1, TS-ent2-Base-Step1. 
Our computational results favor the formation of the product ent2 in contrast to the experimental findings where the formation of $\mathbf{2}$ is favored. Nevertheless, transition structures which include methanol (base-catalyzed mechanism) have large conformational space and flexibility, therefore, further investigation is very demanding and is beyond the scope of this study, which aims at clarifying the feasibility of nucleophilic versus base-catalyzed pathways for alcoholytic ring opening of cyclic anhydrides.

On the other hand, the transition structure for the nucleophilic mechanism is very tight and the lack of methanol renders the conformational space of this structure quite limited. Thus we can safely predict that the base-catalysis mechanism is preferred over the nucleophilic mechanism for the desymmetrization of cyclic meso-anhydrides by chiral amino alcohols.

\section{CONCLUSIONS}

The asymmetric ring opening of cyclic meso-anhydride $\mathbf{1}$ catalyzed by amino alcohol $\mathbf{3}$ is proposed to proceed by the general base catalysis pathway. The general base catalysis pathway is favored energetically $(\mathrm{B} 3 \mathrm{LYP} / 6-31+\mathrm{G}(\mathrm{d}, \mathrm{p}))$ by $26.8 \mathrm{kcal} / \mathrm{mol}(23.4 \mathrm{kcal} / \mathrm{mol}$ in toluene) over the nucleophilic catalysis. These results have also been confirmed with the MPW1B95, MPWB1K and M05-2X methodologies. The addition of 3 equivalents of methanol stabilizes the reaction by $2.2 \mathrm{kcal} / \mathrm{mol}$ through the formation of hydrogen bonds of the peripheral methanols. These reactions have also been modeled in two solvents (toluene and acetone) with different polarities. The stereoselectivity in base catalysis is found to be dependent on the relative orientation of the catalyst with respect to the anhydride and methanol. Overall, the results suggest that the concerted general base catalysis is favored over the nucleophilic catalysis mechanism. 


\section{ACKNOWLEDGEMENTS}

We are grateful to the NIH-FIRCA project (5R03TW007177-02) and to NIGMS, NIH GM36700 to KNH. Computing resources used in this work were provided by the TUBITAK ULAKBIM High Performance and Grid Computing Center and the National Center for High Performance Computing of Turkey (UYBHM) under grant number 20492009. The support of the Boğaziçi University Research Foundation under grant number 06HB505 is gratefully acknowledged. The authors thank Prof. Carsten Bolm for helpful comments, discussions and suggestions.

Keywords: cyclic meso-anhydrides, $\beta$-amino alcohols, nucleophilic catalysis, general base catalysis, asymmetric ring opening

\section{References}

[1] a) A. C. Spivey, B. I. Andrews, Angew. Chem. Int. Ed. 2001, 40, 3131-3134; b) Y. Chen, P. McDaid, L. Deng, Chem. Rev. 2003, 103, 2965-2983; c) I. Atodiresei, I. Schiffers, C. Bolm, Chem. Rev. 2007, 107, 5683-5712.

[2] For a general overview on desymmetrizations, see: M. C. Willis, J. Chem. Soc., Perkin Trans. 1 1999, 1765-1784.

[3] C. H. Wong and G. M. Whitesides, in Enzymes in Synthetic Organic Chemistry, J. E. Baldwin and P. D. Magnus, Eds., Oxford: Elsevier, 1994.

[4] For selected recent contibutions, see: a) A. Peschiulli, Y. Gun'ko, S. J. Connon, J. Org. Chem. 2008, 73, 2454-2457; b) T. Ivsic, Z. Hamersak, Tetrahedron: Asymmetry 2009, 20, 1095-1098; c) T. Honjo, T. Tsumura, S. Sano, Y. Nagao, K. Yamaguchi, Y. Sei, Synlett 2009, 3279-3282; d) S. H. Oh, H. S. Rho, J. W. Lee, J. E. Lee, S. H. Youk, J. Chin, C. E. Song, Angew. Chem. 2008, 120, 7990-7993; Angew. Chem. Int. Ed. 2008, 47, 7873-7875; e) H. S. Rho, S. H. Oh, J. W. Lee, J. Y. Lee, J. Chin, C. E. Song, Chem. Commun. 2008, 1208-1210; f) S.-X. Wang, F.-E. Chen, Adv. Synth. Catal. 2009, 351, 
$547-552$.

[5] a) R. A. Aitken, J. Gopal, J. A. Hirst, J. Chem. Soc. Chem. Commun 1988, 632-634;

b) R. A. Aitken, J. Gopal, Tetrahedron: Asymmetry 1990, 1, 513-516.

[6] F. Bigi, S. Carloni, R. Maggi, A. Mazzacani, G. Sartori, G. Tanzi, J. Mol. Cat. A 2002, 182, 533-539.

[7] a) J. Hiratake, Y. Yamamaoto, J. Oda, J. Chem. Soc. Chem. Commun. 1985, $1717-$ 1719; b) J. Hiratake, M. Inagaki, Y. Yamamoto, J. Oda, J. Chem. Soc. Perkin Trans. 1987, 1053-1058.

[8] a) S. Mizuta, M. Sadamori, T. Fujimoto, I. Yamamoto, Angew. Chem. Int. Ed. 2003, 42, 3383-3385; b) B. L. Hodous, J. C. Ruble, G. C. Fu, J. Am. Chem. Soc. 1999, 121, 2637-2638; c) C. E. Cannizzaro, T. Strassner, K. N. Houk, J. Am. Chem. Soc. 2001, $123,2668-2669$.

[9] G. Vayner, Ph.D. Dissertation, UCLA, 2003.

[10] Y. Takano, K. N. Houk, J. Phys. Chem. A. 2004, 108, 11740-11751.

[11] S. Xu, I. Held, B. Kempf, H. Mayr, W. Steglich, H. Zipse, Chem. Eur. J. 2005, 111, 4751-4757.

[12] Zipse and co-workers have also calculated the benzhydryl cation and benzyl cation affinities of quinine and its building blocks at the MP2(FC)/6-31+G(2d,p)//B3LYP/6$31 \mathrm{G}(\mathrm{d})$ level to explore why benzyl bromide reacts selectively at the $\mathrm{Nsp}^{3}$ center of cinchona alkaloids while benzhydrylium ions react selectively at the $\mathrm{Nsp}^{2}$ center. $\mathrm{M}$. Baidya, M. Horn, H. Zipse, H. Mayr, J. Org. Chem. 2009, 74, 7157-7164.

[13] a) C. Bolm, A. Gerlach, C. Dinter, Synlett 1999, 195-197; b) C. Bolm, I. Schiffers, C. L. Dinter,A. Gerlach, J. Org. Chem. 2000, 65, 6984-6991; c) C. Bolm, I. Schiffers, C. L. Dinter, L. Defrère, A. Gerlach, G. Raabe, Synthesis 2001, 1719 - 1730; d) C. Bolm, I. Schiffers, I. Atodiresei, C. P. R. Hackenberger, Tetrahedron:Asymmetry 2003, 14, 3455-3467; e) C. P. R. Hackenberger, I. Schiffers, J. Runsinck, C. Bolm, J. Org. Chem. 2004, 69, 739 - 743; f) C. Bolm, I. Atodiresei, I. Schiffers, Org. Synth. 2005, 82, 120 125; g) T. Rantanen, I. Schiffers, C. Bolm, Org. Process Res. Dev. 2007, 11, 592 - 597.

[14] T. Rantanen, dissertation at RWTH Aachen University, 2007.

[15] For recent computational studies on anhydride openings with alkaloid- and diaminederived thioureas, see refs. $4 \mathrm{~d}-\mathrm{f}$.

[16] a) R. G. Parr, W. Yang, Density-functional theory of atoms and molecules, Oxford Univ. Press, Oxford, 1989; b) P. Hohenberg, W. Kohn, Phys. Rev. 1964, 136, B 864; c) W. Kohn, L. Sham, J. Phys. Rev. 1965, A1133-A1138. 
[17] a) A. D. Becke, J. Chem. Phys. 1993, 98, 5648-5652; b) C. Lee, W. Yang, R. G. Parr, Phys. Rev. 1988, B37, 785-789.

[18] C. Gonzáles, H. B. Schlegel, J. Phys. Chem. 1990, 94, 5523-5527.

[19] Gaussian 03, Revision B.05, M. J. Frisch, G. W. Trucks, H. B. Schlegel,G. E. Scuseria, M. A. Robb, J. R. Cheeseman, J. A. Montgomery, Jr., T. Vreven, K. N. Kudin, J. C. Burant, J. M. Millam, S. S. Iyengar, J. Tomasi,V. Barone, B. Mennucci, M. Cossi, G. Scalmani, N. Rega, G. A. Petersson, H. Nakatsuji, M. Hada, M. Ehara, K. Toyota, R. Fukuda, J. Hasegawa, M. Ishida, T. Nakajima, Y. Honda, O. Kitao, H. Nakai, M. Klene, X. Li, J. E. Knox, H. P. Hratchian, J. B. Cross, V. Bakken, C. Adamo, J. Jaramillo, R. Gomperts, R. E. Stratmann, O. Yazyev, A. J. Austin, R. Cammi, C. Pomelli,J. W. Ochterski, P. Y. Ayala, K. Morokuma, G. A. Voth, P. Salvador, J. J. Dannenberg, V. G. Zakrzewski, S. Dapprich ,A. D. Daniels, M. C. Strain, O. Farkas ,D. K. Malick, A. D. Rabuck, K. Raghavachari, J. B. Foresman, J. V. Ortiz, Q. Cui, A. G. Baboul, S. Clifford, J. Cioslowski, B. B. Stefanov, G. Liu, A. Liashenko, P. Piskorz, I. Komaromi, R. L. Martin, D. J. Fox, T. Keith, M. A. Al-Laham, C. Y. Peng, A. Nanayakkara, M. Challacombe, P. M. W. Gill, B. Johnson, W. Chen, M. W. Wong, C. Gonzalez, J. A . Pople, Gaussian, Inc., Wallingford CT, 2004.

[20] Y. Zhao, D. G. Truhlar, J. Phys. Chem. A 2004, 108, 6908-6918.

[21] Y. Zhao, N. E. Schultz,D. G. Truhlar, J. Chem. Theory Comput. 2006, 2, 364-382.

[22] a) J. Tomasi, B. Mennucci, E. Cance`s, J. Mol. Struct.: THEOCHEM 1999, 464, 211 226; b) M. T. Cance`s, B. Mennucci, J. Tomasi, J. Chem. Phys. 1997, 107, 3032-3041 ; c) B. Mennucci, B. Tomasi, J., J. Chem. Phys. 1997, 106, 5151-5158; d) B. Mennucci,E. Cance`s, J. Tomasi, J. Phys.Chem. B 1997, 101, 10506-10517. 